\title{
PRODUÇÃO DE MUDAS A PARTIR DE MINIESTACAS DE 38 VARIEDADES DO CRUZAMENTO DA BATATA-DOCE LONDRINA E URUGUAIANA
}

\author{
Amarílis Beraldo Rós ${ }^{1}$, Andréia Cristina Silva Hirata ${ }^{1}$ \\ ${ }^{1}$ Agência Paulista de Tecnologia dos Agronegócios - APTA, Polo Regional da Alta Sorocabana, Presidente Prudente, SP. \\ e-mail: amarilis@apta.sp.gov.br, andreiacs@apta.sp.gov.br \\ Agência de Fomento: Agência Paulista de Tecnologia dos Agronegócios
}

\section{RESUMO}

A batata-doce é uma cultura de grande importância e trabalhos de melhoramento genético são necessários. Cada planta oriunda de uma semente botânica é uma nova cultivar, sendo importante sua multiplicação. Nesse trabalho objetivou-se avaliar a produção de mudas de batatadoce a partir de miniestacas oriundas de variedades diferentes provenientes de pais semelhantes. Os tratamentos foram constituídos de miniestacas de 38 variedades e de seus pais Londrina e Uruguaiana. O delineamento experimental foi em blocos casualizados, com três repetições. Foram avaliadas: percentagem de miniestacas brotadas e sobrevivência das mudas após transplantio. A média de miniestacas brotadas foi de $91,4 \%$. A taxa de sobrevivência no campo foi superior a $99 \%$. As variedades diferiram principalmente quanto à brotação de miniestacas (de $100 \%$ a $62,9 \%$ ). Logo, a produção de mudas a partir de miniestacas é uma ferramenta viável para multiplicação de material genético do cruzamento das variedades Londrina e Uruguaiana em programas de melhoramento.

Palavras-chave: Ipomoea batatas (L.) Lam., enraizamento, estaca, melhoramento genético, multiplicação.

\section{MINI-CUTTINGS SEEDLINGS PRODUCTION OF 38 VARIETIES FROM THE CROSS BETWEEN LONDRINA AND URUGUAIANA SWEET POTATO CULTIVARS}

\begin{abstract}
Sweet potatoes are a very important crop and genetic improvement works are necessary. Each plant originated from a botanical seed is a new cultivar, being important its multiplication. The objective of this work was to evaluate the production of sweet potato seedlings from mini-cuttings from different varieties from the same parents. The treatments consisted of mini-cuttings of 38 varieties and of their Londrina and Uruguaiana parents. The experimental design was in randomized blocks, with three replications. The following characteristics were evaluated: percentage of mini-rooted cutting and survival of seedlings after transplanting. The average minirooted cuttings was $91.4 \%$. The survival rate in the field was above $99 \%$. However, there was difference among the varieties mainly regarding the mini-rooted cuttings (values between $100 \%$ and $62.9 \%$ ). It was concluded that the production of seedlings from mini-cuttings is a viable tool for genetic material multiplication from Londrina and Uruguaiana varieties crossing in programs of improvement.
\end{abstract}

Keywords: Ipomoea batatas (L.) Lam., rooting, cutting, breeding, multiplication. 


\section{INTRODUÇÃO}

A batata-doce é o sexto alimento mais importante no mundo, perdendo apenas para arroz, trigo, batata, milho e mandioca (CIP, 2018). Seu cultivo visa, principalmente, a segurança alimentar em função de suas raízes tuberosas, bem como geração de renda (DIAZ et al., 1996; TAIRO et al., 2004). É a cultura que abastece mais pessoas por unidade de área (OKADA et al., 2002). Segundo Rós et al. (2012), em condições técnicas adequadas, a cultura pode produzir mais de $40 \mathrm{t} \mathrm{ha}^{-1}$ de raízes tuberosas.

A cultura apresenta grande importância para o Brasil, sendo cultivada em todas as regiões brasileiras, com destaque para as regiões Sul e Sudeste, sendo os Estados de Rio Grande do Sul e São Paulo os maiores produtores (IBGE, 2016). No entanto, a produtividade da cultura está muito aquém de seu potencial, sendo interessante programas de melhoramento genético para seleção de materiais com elevada produtividade em condições nem sempre adequadas.

Em Presidente Prudente/SP, onde a cultura tem expressiva importância têm sido conduzidos trabalhos de melhoramento genético por meio do cultivo de sementes botânicas. Segundo Jones (1986), sementes botânicas derivadas de uma mesma planta são geneticamente diferentes umas das outras, cada uma sendo, potencialmente, uma nova cultivar. Como cada nova variedade é oriunda de apenas uma planta há pouco material vegetativo, sendo necessária sua multiplicação por meio de uso de miniestacas, técnica comprovada por Rós et al. (2011) como viável para a cultura.

No entanto, diferentes cultivares apresentam diferenças quanto a porcentagem de estacas enraizadas e sua sobrevivência no campo (RÓs et al., 2011).

O presente trabalho teve por objetivo avaliar a produção de mudas de batata-doce a partir de miniestacas oriundas do cruzamento das variedades Londrina e Uruguaiana.

\section{METODOLOGIA}

O trabalho foi realizado em duas etapas. A primeira etapa (produção de plantas enraizadas em bandejas) foi realizada em casa de vegetação localizada no Polo Regional da Alta Sorocabana APTA - na cidade de Presidente Prudente - São Paulo, de março a abril de 2018. A segunda etapa foi realizada após o transplante para local permanente em abril de 2018. As mudas para a produção de miniestacas foram obtidas de plantas originárias de estacas de plantas de batatadoce oriundas de sementes botânicas. Essas plantas fazem parte do Programa de Melhoramento Genético de Batata-doce do Polo Regional da Alta Sorocabana. Os tratamentos consistiram de miniestacas de 38 variedades de batata-doce (numeradas de 01 a 38) oriundas do cruzamento das variedades Uruguaiana e Londrina e miniestacas dessas duas últimas.

O delineamento experimental para as duas fases foi em blocos casualizados, com três repetições. Para a primeira fase foram utilizadas bandejas de poliestireno expandido com 128 células, sendo utilizadas apenas 64 células de cada bandeja por parcela. As bandejas foram preenchidas com substrato comercial Bioplant ${ }^{\circledR}$ e posicionadas em bancadas dentro da estufa. Segmentos com dois nós foram removidos da parte terminal de cada ramo (até $0,3 \mathrm{~m}$ em cada um dos 40 materiais). As folhas foram retiradas com uma tesoura de poda sem danificar as gemas. Foi enterrada uma gema por estaca.

A porcentagem de plantas brotadas foi avaliada aos 10 e 18 dias após o plantio (DAP) em bandeja. Foram consideradas miniestacas brotadas aquelas com pelo menos uma folha de comprimento igual ou maior que $1 \mathrm{~cm}$. Para a segunda etapa, as miniestacas foram retiradas das bandejas e transplantadas em leiras no campo, com espaçamento de 0,3 $\mathrm{m}$ entre plantas e 0,9 $\mathrm{m}$ entre linhas. 0 transplantio ocorreu aos 22 dias após o plantio nas bandejas. Cada parcela consistiu de duas fileiras de 20 plantas cada, totalizando 40 plantas. Para a avaliação da sobrevivência das plântulas foram consideradas as plantas sobreviventes aos dez dias após o transplante. 
Os dados foram processados pela equação arcseno $(x / 100)^{1 / 2}$ e submetidos à análise de variância pelo teste $\mathrm{F}$ e as médias comparadas pelo teste de agrupamento de Scott-Knott a $5 \%$ de probabilidade.

\section{RESULTADOS}

Para todas as características avaliadas, foram observadas diferenças significativas (Tabela 1). As $10 \mathrm{DAP}$, as variedades foram separadas em cinco grupos, enquanto aos $18 \mathrm{DAP}$, em apenas quatro. Em miniestacas de 18 variedades $(01,02,04,05,06,09,12,19,20,21,27,28,29,30,38$, Londrina e Uruguaiana) foi verificada alta porcentagem de brotação, com valores superiores a $90 \%$, independentemente do tempo de avaliação (10 DAP ou 18 DAP). Outras seis variedades atingiram brotações superiores a $90 \%$ aos 18 DAP.

Por outro lado, nove variedades $(01,04,05,20,21,28,38$, Londrina e Uruguaiana) apresentaram 100\% de brotação aos 10 DAP e/ou 18 DAP. Apenas cinco materiais $(14,17,25,26$ e 32) apresentaram valores inferiores a 75\%. Foi verificado que cinco variedades $(08,13,14,15$ e 34) apresentaram porcentagem de brotação aos 10 DAP superior aos valores em 18 DAP.

As variedades Londrina e Uruguaiana apresentaram elevada porcentagem de brotação (100 e 99,6\%, respectivamente). 
Tabela 1. Porcentagens de miniestacas brotadas e sobrevivência de mudas de variedades de batata-doce no campo.

\begin{tabular}{|c|c|c|c|}
\hline Variedade & $\begin{array}{c}\text { Estacas } \\
\text { brotadas } \\
10 \text { DAP }^{1} \\
\end{array}$ & $\begin{array}{c}\text { Estacas } \\
\text { brotadas } \\
18 \text { DAP }^{1}\end{array}$ & $\begin{array}{c}\text { Mudas } \\
\text { sobreviventes } \\
10 \text { DAT }^{1} \\
\end{array}$ \\
\hline & \multicolumn{3}{|c|}{ |-----------------------\%"------------------------ } \\
\hline 28 & $100 \mathrm{~A}$ & $100 \mathrm{~A}$ & $99,6 \mathrm{~A}$ \\
\hline Uruguaiana & $100 \mathrm{~A}$ & $99,6 \mathrm{~A}$ & $100 \mathrm{~A}$ \\
\hline 27 & $99,6 \mathrm{~A}$ & $96,2 \mathrm{~B}$ & $99,6 \mathrm{~A}$ \\
\hline Londrina & $99,6 \mathrm{~A}$ & $100 \mathrm{~A}$ & $100 \mathrm{~A}$ \\
\hline 05 & $99,6 \mathrm{~A}$ & $100 \mathrm{~A}$ & $100 \mathrm{~A}$ \\
\hline 20 & $99,2 \mathrm{~A}$ & $100 \mathrm{~A}$ & $100 \mathrm{~A}$ \\
\hline 38 & $97,1 \mathrm{~B}$ & $100 \mathrm{~A}$ & $93,8 \mathrm{~B}$ \\
\hline 01 & $96,1 \mathrm{~B}$ & $100 \mathrm{~A}$ & $100 \mathrm{~A}$ \\
\hline 02 & $96,1 \mathrm{~B}$ & $99,6 \mathrm{~A}$ & $100 \mathrm{~A}$ \\
\hline 04 & $96,1 \mathrm{~B}$ & $100 \mathrm{~A}$ & $100 \mathrm{~A}$ \\
\hline 09 & $95,8 \mathrm{~B}$ & $97,5 \mathrm{~B}$ & $100 \mathrm{~A}$ \\
\hline 36 & $95,4 \mathrm{~B}$ & $95,6 \mathrm{~B}$ & $96,3 \mathrm{~B}$ \\
\hline 06 & $94,5 \mathrm{C}$ & $97,0 \mathrm{~B}$ & $100 \mathrm{~A}$ \\
\hline 12 & $93,8 \mathrm{C}$ & $99,6 \mathrm{~A}$ & $100 \mathrm{~A}$ \\
\hline 19 & $93,8 \mathrm{C}$ & $99,6 \mathrm{~A}$ & $100 \mathrm{~A}$ \\
\hline 21 & $91,9 \mathrm{C}$ & $100 \mathrm{~A}$ & $100 \mathrm{~A}$ \\
\hline 34 & $90,8 \mathrm{C}$ & $87,8 \mathrm{C}$ & $99,6 \mathrm{~A}$ \\
\hline 30 & $90,0 \mathrm{C}$ & $92,4 \mathrm{C}$ & $100 \mathrm{~A}$ \\
\hline 29 & $90,0 \mathrm{C}$ & $99,6 \mathrm{~A}$ & $96,3 \mathrm{~B}$ \\
\hline 31 & $88,4 \mathrm{C}$ & $93,2 \mathrm{C}$ & $91,2 \mathrm{~B}$ \\
\hline 16 & $88,4 \mathrm{C}$ & $89,9 \mathrm{C}$ & $100 \mathrm{~A}$ \\
\hline 18 & $87,5 \mathrm{C}$ & $88,7 \mathrm{C}$ & $100 \mathrm{~A}$ \\
\hline 10 & $88,8 \mathrm{C}$ & $96,2 \mathrm{~B}$ & $100 \mathrm{~A}$ \\
\hline 03 & $88,0 \mathrm{C}$ & $89,0 \mathrm{C}$ & $100 \mathrm{~A}$ \\
\hline 08 & $86,0 \mathrm{C}$ & $95,1 \mathrm{~B}$ & $100 \mathrm{~A}$ \\
\hline 35 & $85,5 \mathrm{C}$ & $88,9 \mathrm{C}$ & $93,8 \mathrm{~B}$ \\
\hline 15 & $85,2 \mathrm{C}$ & $94,5 \mathrm{~B}$ & $100 \mathrm{~A}$ \\
\hline 13 & $81,6 \mathrm{D}$ & $99,6 \mathrm{~A}$ & $100 \mathrm{~A}$ \\
\hline 11 & $80,9 \mathrm{D}$ & $84,1 \mathrm{C}$ & $100 \mathrm{~A}$ \\
\hline 33 & $79,8 \mathrm{D}$ & $86,9 \mathrm{C}$ & $100 \mathrm{~A}$ \\
\hline 37 & $76,0 \mathrm{D}$ & $85,0 \mathrm{C}$ & $99,6 \mathrm{~A}$ \\
\hline 07 & $74,2 \mathrm{D}$ & $88,5 \mathrm{C}$ & $100 \mathrm{~A}$ \\
\hline 22 & $74,1 \mathrm{D}$ & $86,8 \mathrm{C}$ & $100 \mathrm{~A}$ \\
\hline 24 & $70,4 \mathrm{D}$ & $98,5 \mathrm{~B}$ & $100 \mathrm{~A}$ \\
\hline 25 & $70,4 \mathrm{D}$ & $71,5 \mathrm{D}$ & $100 \mathrm{~A}$ \\
\hline 14 & $67,0 \mathrm{E}$ & $62,9 \mathrm{D}$ & $100 \mathrm{~A}$ \\
\hline 32 & $62,6 \mathrm{E}$ & 73,7 D & $99,4 \mathrm{~A}$ \\
\hline 17 & $60,0 \mathrm{E}$ & $62,9 \mathrm{D}$ & $100 \mathrm{~A}$ \\
\hline 23 & $58,0 \mathrm{E}$ & $82,0 \mathrm{C}$ & $100 \mathrm{~A}$ \\
\hline 26 & $55,7 \mathrm{E}$ & $72,8 \mathrm{D}$ & $100 \mathrm{~A}$ \\
\hline & $C V=5,45 \%$ & $\begin{array}{c}C V= \\
5,02 \%\end{array}$ & $C V=2,79 \%$ \\
\hline
\end{tabular}

Médias seguidas de letras diferentes na coluna diferem entre si pelo teste de Scott-Knott, a 5\% de probabilidade. ${ }^{1}$ valores não transformados. 
Com relação a porcentagem de sobrevivência no campo, todas as variedades apresentaram valores acima de $91 \%$, sendo separadas pelo teste em dois grupos: acima e abaixo de $99 \%$.

\section{DISCUSSÃO}

A alta porcentagem de enraizamento de miniestacas foi favorecida pelo uso de estacas retiradas de parte jovem da planta que, segundo Hartman et al. (1997), apresentam menores níveis de lignificação e células meristemáticas com metabolismo mais ativo, favorecendo o enraizamento e brotação.

A morte de miniestacas após a primeira avaliação foi, provavelmente, devido a suscetibilidade à desidratação ou à baixa quantidade de reservas a serem utilizadas durante o processo de emissão de raízes e folhas.

A elevada porcentagem de brotação das variedades Londrina e Uruguaiana está de acordo com os resultados encontrados por Rós-Golla et al. (2010), os quais verificaram porcentagem de enraizamento superior a $97 \%$ dessas variedades em bandejas de 72 e 128 células. E, embora esses materiais sejam pais dos demais, a característica de elevada porcentagem de brotação não ocorreu em todas as variedades descendentes pois, segundo Zietemann e Roberto (2007), as variedades apresentam características genéticas, fisiológicas e metabólicas específicas de cada genótipo. Nacata et al. (2014) também verificaram diferenças na sobrevivência e enraizamentos de estacas herbáceas retiradas de diferentes cultivares de caramboleira.

A elevada taxa de sobrevivência no campo de mudas de batata-doce produzidas em bandeja também foi verificada por Rós et al. (2011) ao estudar 30 clones e 29 deles apresentarem percentagem de sobrevivência acima de $90 \%$.

\section{CONCLUSÕES}

Miniestacas de batata-doce provenientes de plantas oriundas do cruzamento das variedades Londrina e Uruguaiana apresentam elevada taxa de brotação e diferem entre si quanto a porcentagem de brotação e sobrevivência no campo.

A produção de mudas a partir de miniestacas é uma ferramenta viável para multiplicação de material genético em programas de melhoramento da batata-doce.

\section{AGRADECIMENTOS}

Agradecemos à Fundação de Amparo à Pesquisa do Estado de São Paulo pelo suporte financeiro que permitiu a realização desse trabalho

\section{REFERÊNCIAS}

CIP - INTERNACIONAL POTATO CENTER. Sweetpotato facts and figures. Lima, 2018. Disponível em: $<$ https://cipotato.org/crops/sweetpotato/sweetpotato-facts-and-figures/>. Acesso em 13 jun. 2018.

DIAZ, J.; SCHMIEDICHE, P.; AUSTIN, D.F. Polygon of crossability between eleven species of Ipomoea: section Batatas (Convolvulaceae). Euphytica, v.88, n.3, p.189-200, 1996. https://doi.org/10.1007/BF00023890

HARTMAN, H.T.; KESTER, D.E.; FRED JR, T.D.; GENEVE, R.L. Plant propagation: principles and practices. New Jersey: Prentice Hall, 1997. 770 p.

IBGE. Sistema IBGE de recuperação automática. 2016. Disponível em: <http://www2.sidra.ibge.gov.br/bda/tabela/listabl.asp?c=1612\&z=t\&o=11>. Acesso em: 31 jan. 2017. 
JONES, A. Sweet potato breeding. In: BASSET, M.J. (ed.). Breeding Vegetable Crops. Westport: AVI, 1986. p.1-35.

NACATA, G.; ANDRADE, R.A.de; JASPER, S.P.; PRATA, R.S. Propagação de variedades de caramboleira por estaquia herbácea. Revista Brasileira de Fruticultura, v.36, n.1, p. 248-253, 2014. https://doi.org/10.1590/0100-2945-237/13

OKADA, Y.; NISHIGUCHI, M.; SATO, A.; KIMURA, T.; MORI, M.; HANADA, K.; SAKAI, J.; MATSUDA, Y.; MURATA, T. Murata Inheritance and stability of the virus-resistant gene in the progeny of transgenic sweet potato. Plant breeding, v.121, n.3, p.249-253, 2002. https://doi.org/10.1046/i.1439-0523.2002.00709.x

RÓS, A.B.; HIRATA, A.C.S.; SANTOS, H.S. Avaliação da produtividade de plantas de batata-doce oriundas de matrizes livres de vírus. Revista Brasileira de Ciências Agrárias, v.7, n.3, p.434-439, 2012. https://doi.org/10.5039/agraria.v7i3a1716

RÓS, A.B.; MONTES, S.M.N.M.; NARITA, N.; TAVARES FILHO, J. Technical viability of the production of sweet potato plantlets in trays. Semina: Ciências Agrárias, v. 32, n.4, p. 1423-1428, 2011. https://doi.org/10.5433/1679-0359.2011v32n4p1423

RÓS-GOlla, A.; SILVA HIRATA, A. C.; ARAÚJO, H. S. de; SANTOS, V. B. dos; NARITA, N. Multiplicação de material vegetativo de batata-doce em diferentes bandejas e produção de raízes. Apta Regional, Campinas, Mar. 2010. Disponível em: <http://aptaregional.sp.gov.br/artigo.php?id_artigo=733>. Acesso em: 17 mai. 2018.

TAIRO, F.; KULLAYA, A.; VALKONEN, J.P.T. Incidence of viruses infecting sweetpotato in Tanzania. Plant Disease, v.88, n.9, p.916-920, 2004. https://doi.org/10.1094/PDIS.2004.88.9.916

ZIETEMANN, C.; ROBERTO, S. R. Produção de mudas de goiabeira (Psidium guajava L.) em diferentes substratos. Revista Brasileira de Fruticultura, Jaboticabal, v. 29, n. 1, p. 137-142, 2007. 